\title{
La causa jurídica de las cláusulas abusivas ${ }^{\star}$
}

\author{
The Legal Cause of Unfair Terms \\ A Causa Jurídica das Cláusulas Abusivas
}

\section{Maximiliano ARANGo Grajales ${ }^{*}$}

FeCHA DE RECEPCIÓN: 30 de MARZo de 2015. FeCHA DE ACEPTACIÓN: 05 dE OCtUBRE DE 2015

Doi: dx.doi.org/10.12804/esj18.01.2016.08

Para citar este artículo: Arango, M. (2016). La causa jurídica de las cláusulas abusivas. Estudios Socio-Jurídicos, 18(1), 243 -266.

Doi: dx.doi.org/10.12804/esj 18.01.2016.08

\section{RESUMEN}

Las cláusulas abusivas injustificadas no pertenecen al campo del abuso del Derecho, pues no se está ante la teoría del riesgo potencial y mucho menos se ha presentado un daño. Las cláusulas abusivas injustificadas pertenecen al campo del principio de conmutatividad del contrato y es por medio de este que el criterio de desequilibrio normativo del contrato cobra sentido. La corrección de este tipo de cláusulas no depende de partes débiles o abusos, sino, más bien, de la existencia de un desequilibrio: la ausencia de causa en el contrato.

Palabras clave: contrato, cláusulas abusivas, causa, equivalencia.

\begin{abstract}
Unfair terms are outside the field of abuse. There's not a potential risk of damage, there's not an injury caused. Unfair terms belong to the field of the principle of equivalency of the contract. And through it, that the criterion of regulatory imbalance of the contract takes on meaning. The correction of such unfair clauses does not depend on weak parts or abuse but rather the existence of a breach of equivalence: an absence of consideration in the contract.
\end{abstract}

Keywords: contract, unfair clauses, consideration, equivalency.

\section{RESUMO}

As cláusulas abusivas-injustificadas não pertencem ao campo do abuso do direito, pois não se está ante a teoria do risco potencial e, muito menos, se tem apresentado um dano. As cláusulas abusivas-injustificadas pertencem ao campo do princípio de comutatividade do contrato. E é através dele, que o critério de desequilíbrio normativo do contrato adquire sentido. A correção então deste tipo de cláusulas não depende de partes fracas ou abusos, mas, ao contrário, da existência de um desequilíbrio: de uma ausência de causa no contrato.

Palavras-chave: Contrato, Cláusulas abusivas, Causa, Equivalência.

* Un enorme agradecimiento al profesor Camilo Rodríguez Yong, pues sus brillantes comentarios hicieron coherente este texto. A veces, el exceso de palabras ciega al mismo autor.

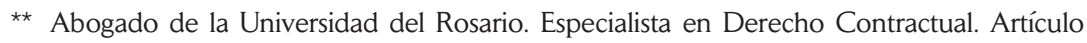
de Reflexión. Abogado Litigando en Sanabria Gómez Abogados. Correo electrónico: marango@ sanabriagomez.com 


\section{Introducción}

"El contrato es de, por y para todas las partes que lo construyeron de consuno a través de su consentimiento.

O no es contrato" (Caumont, 2008, p. 149)

El contrato es un arquetipo diseñado por los particulares para regir sus actitudes e intereses. Las necesidades y preocupaciones de ambas partes de la relación deben verse colegidos en el contrato; de lo contrario, no se estaría ante tal, por ser para uno y de uno solo de los signatarios. El contrato es fruto de la autonomía de la voluntad, por principio. Cuando no lo es, se opone a los intereses de los firmantes, tanto es así, que la ley ha previsto una serie de categorías correctivas a problemas tan variados como los vicios del consentimiento, la excesiva onerosidad y las cláusulas abusivas (Pérez Vives, 1953). ${ }^{1}$

Las cláusulas abusivas han sido entendidas como aquellas previsiones particulares que rompen el equilibrio justo de las relaciones privadas, cuyo efecto es, en principio, la ineficacia de pleno Derecho. De ahí que sean el abuso del Derecho y la buena fe los referentes históricos y de naturaleza jurídica que la doctrina ha acogido en explicación de este tipo anómalo de cláusulas.

El abuso del Derecho - en este caso, el abuso a contratar- se muestra en tanto no hay una violación de la libertad contractual en su objeto y alcance jurídico, pero en la práctica, se presenta una extralimitación de la voluntad privada que rompe la finalidad de la norma. "No todo lo lícito es honrado", explica el jurista Paulo en el Digesto (Digesto. 50.17.144.) o malitiis non estindulgendum (Digesto, 6, 1, 38) e incluso, summum jus summa injuria (Ciceron, de officiis, 1, 10, 33, citado en D'Ors, 1968). À la limite, el abuso es una restricción a la voluntad de las partes, en el sentido de hacerla obedecer la finalidad económica y social, que nunca será romper el equilibrio en las relaciones privadas; en caso contrario, se abusa (Pérez Vives, 1968). Una lesión teleológica es prohibida y el daño inferido debe ser reparado 
(De Cupis, 1975). Objetivamente, el abuso es lícito; subjetivamente, no: se requiere una intención de daño (Pérez Vives, 1953) o una imprudencia que lo crea, pero, ¿puede haber abuso sin daño, solo con la intención? ¿Cómo conciliar el hecho de que una cláusula aún no ejecutada pueda configurar responsabilidad? El problema reside en los criterios de identificación de la sustancia con su accidente, porque, desde la ley colombiana, el abuso no es dable sin daño, como también en el resto de legislaciones (Malaurie, Aynès y Stoffel-Munck, 2011).

La noción que se ha acogido de cláusulas abusivas puede esclarecer este punto, pues su fundamento orbita en torno al abuso del Derecho. En Francia, las cláusulas abusivas son entendidas como aquellas que generan un desequilibrio entre los derechos que emanan del contrato (Malaurie et al., 2011). En Alemania, la ley tiene dos criterios: primero, es estipulación abusiva la que se aparta de las ideas esenciales de la reglamentación legal. Segundo, la limitación a los derechos y las obligaciones esenciales del contrato predispuesto (Cárdenas, 2009b).

Más cerca, en América, el postulado no ha ido demasiado lejos. En Argentina, la Ley 24240 se refiere a las cláusulas abusivas según la concepción de sus elementos configurativos, mas no las define. Con las enseñanzas de la profesora Estigarribia Bieber (2000), la doctrina dicta: "[...] a priori, podemos sostener que una cláusula predispuesta es abusiva cuando, contrariando el principio de la buena fe, da origen a un desequilibrio significativo, en detrimento del consumidor" (p. 2). El mismo camino ha seguido el pensamiento chileno. ${ }^{2}$

En Colombia, el concepto es muy rico y no se aleja de la tendencia continental. El profesor Laguado (2003) establece que una cláusula abusiva es aquella presente en contratos de adhesión que, en contra de las exigencias de la buena fe, crea un desequilibrio manifiesto entre las obligaciones de las partes.

Es la misma ley la que trae ciertas pistas sobre el entendimiento de las cláusulas abusivas, tanto en aquella de los servicios públicos domiciliarios como en la Ley de protección al consumidor financiero. Con la Ley 1480

2 La Ley 19496 también omite definir las cláusulas abusivas, mas sí dispone que en el sistema existe una serie de disposiciones expresas y taxativas sobre algunas cláusulas y las ataca por el objeto ilícito. 
de 2011, se erige el Estatuto de protección general al consumidor, cuyo Artículo 42 reza:

Son cláusulas abusivas aquellas que producen un desequilibrio injustificado en perjuicio del consumidor y las que, en las mismas condiciones, afecten el tiempo, modo o lugar en que el consumidor puede ejercer sus derechos. Para establecer la naturaleza y magnitud del desequilibrio, serán relevantes todas las condiciones particulares de la transacción particular que se analiza.

Los productores y proveedores no podrán incluir cláusulas abusivas en los contratos celebrados con los consumidores, en caso de ser incluidas serán ineficaces de pleno derecho.

De lo anterior se extraen tres elementos: 1) debe existir un desequilibrio injustificado en perjuicio del consumidor; 2) el desequilibrio se medirá con el rasero de las condiciones particulares del negocio, y 3 ) en caso de estar ante una cláusula abusiva, esta será ineficaz de pleno Derecho. Estamos en el evento de conocer ¿qué tipo de desequilibrio se configura? ¿Aquél propio del abuso del Derecho? Y, de acuerdo con ello, la sanción que acarrearía, porque como se verá, la fuente jurídica del derecho de corrección o sanción no es tan clara como el postulado legal pareciera proponerla.

El problema que se busca resolver en esta disertación es ¿cuál es la fuente jurídica de las cláusulas abusivas? La respuesta está en la diferencia entre la fuente jurídica y la del conflicto. La segunda es previa a la fuente jurídica: aquella es el nacimiento de una estipulación abusiva; esta es el origen de dicho desequilibrio. Se llegará a la conclusión obvia: las cláusulas anómalas son propias de la aplicación de la teoría de la causa, por cuanto son un desequilibrio normativo del contrato, con lo que se obvia la necesidad de presencia de un daño. Primero, se debe establecer el problema conceptual, las causas mediatas del conflicto o de una cláusula abusiva. Luego, la lógica de acoger la causa jurídica sobre el hecho conflictivo.

\section{La fuente jurídica de las cláusulas abusivas}

A toda causa le sigue una consecuencia, pero ¿qué ocurre cuando una causa mediata es confundida con otra que sí es el motor generador del 
conflicto jurídico? Se confunde la figura, se aplican soluciones incompletas $\mathrm{o}$, bien, se tiene que recurrir a métodos de elevada complejidad. Esto es lo que acontece en Colombia y en la doctrina comparada sobre la teoría de las cláusulas abusivas. La disertación expone las causas mediatas e inmediatas. Aquí se buscará dar a conocer la tendencia y lo que ha ocurrido en el sistema jurídico nacional y describir cómo todas las vías adolecen de inexactitud.

\subsection{Tendencias}

El Derecho contiene instituciones propias para determinar cuándo y cómo ha de eliminarse una cláusula abusiva. Desde el punto de vista de la teoría del actor jurídico, se puede apelar a los principios del Derecho como la buena fe y el abuso del Derecho. Por otro lado, también son útiles los vicios del consentimiento, como el dolo - entendido como la actitud malintencionada de imponer un clausulado determinado- o la violencia - expresada en el abuso de la posición negocial-. Todo lo anterior, por principio, genera nulidad relativa y, en su caso, responsabilidad civil precontractual.

Tanto el dolo como la violencia económica tendrían el poder de explotar el temario de cláusulas abusivas, en razón a que la actitud de causar perjuicio o la subordinación de factores económicos no le dejarían otra opción al contratante que asegurar la prestación y someterse a cláusulas anómalas.

Por otra parte, la buena fe es de dos tipos - objetiva y subjetiva-, ambos subnorma de la regla constitucional desde el panorama de la Constitución de $1991^{3}$ y derivada del Derecho romano. Con la base jurídica de comportamiento que impone la buena fe objetiva, todos los contratos han de celebrarse y ejecutarse en marco de esta, ${ }^{4}$ con exigencia de una actitud recta y honrada entre contratantes. El poder negocial no puede derivar en abuso del clausulado contractual porque todo vicio que contenga surge por la deslealtad de una de las partes del contrato. La buena fe deriva la regla del

3 Artículo 83 de la Constitución Política de Colombia

4 La buena fe objetiva encuentra sustento en el Artículo 769 del Código Civil, que la presume en las relaciones jurídicas. Es relevante el Artículo 1603, pues impone que, para la ejecución de los contratos, se debe seguirla. El Artículo 871 del Código de Comercio enuncia esta regla y expande su espectro a la equidad y a la costumbre. Pueden ser nombrados, además, los Artículos 834, 835 y 863 del Código de Comercio. 
abuso del Derecho, es decir, quien abusa rompe también el principio de la buena fe (Pizarro, 2012). El efecto en el uso de la buena fe como corrector de cláusulas abusivas es la nulidad absoluta por violación de un principio constitucional o las respectivas consecuencias en sede de responsabilidad civil contractual o precontractual.

Por último, el abuso del Derecho encuentra asidero en una derivación de la culpa aquiliana traída del Derecho romano. El abuso del derecho es una ampliación del espectro de aplicación de una prerrogativa jurídica y causa daño a otro y quien abusa de sus derechos, tiene la obligación de pagar los daños, según el tenor del Artículo 830 del Código de Comercio.

De acuerdo con la doctrina y la jurisprudencia, el abuso del derecho a contratar configuraría una cláusula abusiva. Quien desequilibra las relaciones del contrato, sin justicia, incurre en un abuso de su derecho de la libertad de confección de contratos, en flagrante violación de un principio general del Derecho. Del tenor de la ley, el abuso es fuente de acción indemnizatoria, pues debe repararse el daño creado por las extralimitaciones en la ejecución de los propios derechos subjetivos.

\subsection{La causa jurídica y la causa del conflicto}

Se han analizado los argumentos que sustentan las previsiones abusivas, pero, ¿son estas las fuentes del derecho de corrección dado a los diversos entes que controlan este tipo de estipulaciones? No. Una cosa son las causas del problema y otra las del Derecho. Los móviles pueden ser variados, mas no son la causa sine qua non de existencia del Derecho, ${ }^{5}$ salvo en muy esporádicos casos, como se verá más adelante.

El problema es de identificación. Usar los vicios del consentimiento no es del todo preciso en sede de cláusulas abusivas y su naturaleza. El dolo requiere una actitud malintencionada y consciente, elemento exótico en las relaciones entre particulares, mucho más excéntricas cuando se argumenta

5 Debido a esta confusión, es difícil para los juzgadores y la doctrina salirse del esquema argumental. El profesor Rodríguez Yong (2013) dice que las cláusulas abusivas pueden estar en cualquier tipo de contrato; no obstante, el argumento que allega es de la decisión arbitral Punto Celular Ltda. c. Comunicación Celular S. A. - Comcel S. A.-, en la que el criterio es la imposición de una cláusula en un contrato que no es de adhesión y aún persiste el criterio de debilidad: imposición negocial en el contrato, criterio restrictivo del cual esta ponencia se aparta diametralmente. 
en relaciones del consumo, que es la gran mayoría de las transacciones comerciales. Ahora bien, la violencia económica es más cercana al conflicto, pero no al Derecho. De un lado, el ambiente más propicio de creación de cláusulas abusivas es el contrato de consentimiento adhesivo; reitera la jurisprudencia que hay presencia de una posición de dominio. El yerro de esto está en que también la doctrina y la jurisprudencia han aceptado la existencia de cláusulas abusivas en contratos entre particulares e individualmente negociados, "Lo abusivo - o despótico- de este tipo de cláusulas que pueden estar presentes en cualquier contrato y no solo en los de adhesión o negocios tipo" (Corte Suprema de Justicia, 2001).

Por otro lado, surge la enorme confusión de esta figura con la buena fe y el abuso del Derecho. Si bien están ligados, no son lo mismo. La violencia vicia el consentimiento; el abuso propicia el derecho de indemnización y la buena fe puede ser creadora de responsabilidad o de nulidad.

[...] obliga a quien impone el contenido negocial, mayormente cuando el contrato es por adhesión o estandarizado, a no abusar de su posición dominante [...] porque de lo contrario estaría faltando a esa buena fe que le impone el sistema jurídico (Corte Suprema de Justicia, 2011b).

Si bien en esta decisión la Corte Suprema de Justicia analiza la circunstancia de violencia económica, la releva a un plano de causa de desequilibrio económico, mas no del derecho de corrección, ya que se acerca a la noción de buena fe para controlar el hecho de haber un desequilibrio del contrato.

La buena fe exige un correcto actuar, un deber de lealtad en las actuaciones que, en la vida del contrato, se traduce en la creación de obligaciones secundarias de conducta a cargo de las partes y en la fase precontractual, en la prohibición de abusar del derecho objetivo a contratar. De allí que la similitud de usos entre la buena fe y el abuso del Derecho haya permitido a los operadores jurídicos acudir a una u otra figura para resolver problemas similares (Gil, 2013). En últimas, es un criterio integrador del contrato, cuya inobservancia hace surgir responsabilidad civil, problema que también comparte con el abuso del Derecho.

El abuso del Derecho es el criterio que más problemas lógicos genera. Primero, es una fuente de obligaciones, pues quien abuse de sus derechos 
se hace deudor de la obligación de reparar el daño, fenómeno llamado acto ilícito sui generis por algún sector de la doctrina (Rengifo, 2014). ¿Qué obligación se crea en presencia de una cláusula abusiva? Ninguna, porque esta se elimina en virtud de la ley y es aquí en donde la jurisprudencia recurre a una tautología: una cláusula es abusiva porque proviene del abuso del Derecho; como este está prohibido, la cláusula es inválida porque lesiona un principio general del sistema jurídico que impone un deber de conducta (Tamayo, 2007). Parece que la argumentación adolece de imprecisión, por cuanto no se puede partir del abuso sin acreditar los elementos del mismo y, en ello, declarar la violación del principio. ¿Cómo saber que una cláusula es violatoria de un principio general del Derecho? La ley especial ha traído los elementos de identificación de una cláusula abusiva y no del abuso y, en ello, se debe recurrir al Artículo 830 del Código de Comercio. Los elementos del abuso del derecho son: la culpa, el daño y el nexo de causalidad.

Como segunda censura, el daño aún no existe. Una cláusula abusiva todavía no se ha ejecutado, razón por la cual no existe uno de los elementos esenciales de la responsabilidad. En palabras de la Corte Suprema de Justicia (1938): “[...] el abuso del derecho sería una especie particular de culpa aquiliana, que puede ir desde el dolo (animus nocendi), hasta el daño ocasionado por la simple negligencia o imprudencia no intencionada".

Se ha sostenido que la potencialidad de daño basta, lo que implica que la necesidad de los elementos del abuso del Derecho para declarar ineficaz una cláusula puede flexibilizarse, pero este es un criterio de identificación que no alcanza a suplir el elemento de daño exigido por la ley. La tesis de la potencialidad del daño, propia de la doctrina del riesgo creado, tiene la finalidad de sustituir el elemento de la responsabilidad en casos excepcionales en los que el tráfico jurídico lo requiere. En otras palabras, una cláusula abusiva pertenece al abuso del Derecho, porque tiene la potencialidad de dañar a uno de los contratantes, al cargarle en exceso dentro del contrato. No obstante, las cláusulas abusivas no solo se gestionan al interior de contratos excepcionales o asimétricos, como se explicará más adelante; las cláusulas abusivas existen en cualquier tipo de contrato, lo que haría que la excepción en recurrir a la potencialidad de daño se vuelva regla.

En este punto es pertinente establecer la confusión entre cláusulas abusivas y prácticas abusivas. Las segundas sí generan daño y son la eje- 
cución de una estipulación, abusiva o no, en llana violación a los intereses de una parte, sin fundamento alguno. El abuso del Derecho es sustento de las prácticas abusivas, de cuyo nombre le hace honra y quien abusa de su derecho debe reparar el daño causado (Gil, 2013). No se abusa si no se ha usado, es decir, ejecutado (Corte Suprema de Justicia, 2013).

Resta decir que el sistema de listas negras no es criterio de identificación de cláusulas abusivas por su naturaleza, debido a que el acaecimiento de una de aquellas hipótesis o ejemplos de control provoca una cláusula ilegal, mas no abusiva. Al ser ilegal, no se está ante el abuso, sino ante una fehaciente violación de la norma, que deriva en objeto ilícito (Cárdenas, 2009a).

Esta ponencia sostiene que cualquiera puede ser la causa del desequilibrio o conflicto: el abuso del derecho a contratar, la violencia, la inaplicación de una actitud recta y honrada, etc., pero solo una es causa de existencia de una cláusula abusiva; sin ella, puede estarse frente a cualquiera de las otras circunstancias del conflicto y no ante una cláusula abusiva. ${ }^{6}$ Emplear el abuso del Derecho, cuando existe una institución jurídica directamente aplicable, por el hecho de violar un principio general, es una solución voluntarista e irrazonable, para citar a Puig Brutau (Corte Suprema de Justicia, 2005). 7 ¿Qué sucede si se está ante una cláusula abusiva que no deriva de abuso, actitud desleal o circunstancias que vician el consentimiento, incluso si no se está ante una de las hipótesis de una lista negra? Igual, queda un medio de control: la teoría de la causa.

\section{De la lógica y la solución}

Las cláusulas abusivas son una quimera. No se han ejecutado, pero el sistema requiere que sean eliminadas del contrato, porque son una forma de desequilibrio. El profesor Pérez Vives (1953) ya había expuesto que la ausencia de causa era el fundamento de eliminación para las cláusulas

6 Por ejemplo, si se está ante la violencia económica, ¿no se estaría ante el vicio del consentimiento y no el abuso y su correlativa ineficacia de pleno Derecho? Este es el tipo de confusiones que se generan al traslapar causas mediatas con inmediatas (Corte Suprema de Justicia, 1994).

7 "Por supuesto que esta regla general no se opone a que, en casos particulares, puede restarse eficacia a una cláusula así diseñada, si se demuestra, por vía de ejemplo, que ella vulnera el principio de autonomía de la voluntad, que es abusiva o leonina" (Corte Suprema de Justicia, 2005). 
leoninas; el punto está en retomar su brillante pensamiento. Primero, como ya se auguró líneas atrás, se demostrará la viabilidad de la perspectiva desde los operadores jurídicos en Colombia y, acto seguido, la causa de las obligaciones, como la esencia operativa de las cláusulas abusivas.

\subsection{El desequilibrio normativo del contrato}

La Ley 1480 de 2011 es el marco de referencia para el ente de control sobre la protección al consumidor. Según el Artículo 59, numeral 14, la autoridad podrá modificar los clausulados adhesivos en relaciones de consumo, sin que lo anterior se considere un control administrativo previo. También se ofrece una lista de cláusulas negras, ${ }^{8}$ en las cuales si alguna previsión del contrato aparece como prohibida, adolece de objeto ilícito y sería eliminada del espectro del contrato (Ley 1480, art. 43).

Se establece la noción de cláusula abusiva, en la que es importante resaltar "aquellas que producen un desequilibrio injustificado en perjuicio del consumidor" (cursivas propias) (Ley 1480, art. 42). Tres elementos se habían extraído en la Introducción: el desequilibrio, la identificación del desequilibrio y su consecuencia. Es, pues, que la naturaleza operativa de una cláusula abusiva reside en el desequilibrio. Esta desigualdad no puede ser otra que aquella paridad normativa dentro del contrato porque, al decir injustificado, no existe otra explicación lógica que aquella que atañe a las prestaciones obligacionales recíprocas de las partes. Como ya se dijo, una lista negra es de estipulaciones ilícitas, independientemente de si son abusivas, pues para esto se requiere pasar por el concepto mismo.

La Superintendencia Financiera adopta una vía parecida a la tomada por la Superintendencia de Industria y Comercio. Es de obligatoria referencia la Circular Externa 039 de 2011, en la que se establecen reglas sobre cláusulas abusivas con fundamento en los Artículos 7 y 11 de la Ley 1328 de 2009, que faculta a la Superintendencia Financiera para producir listas negras de

8 Existe un problema atribuible a todo tipo de sistema de cláusulas negras: el prototípico caso es la prohibición tajante que trae el Estatuto de protección al consumidor sobre las cláusulas de modificación unilateral del contrato, previsiones necesarias para la no petrificación del acto jurídico, pero, por vía del sistema de listas, quedan por fuera del espectro de la libertad particular. Las listas negras, desde arriba, atacan la libertad contractual y, desde abajo, siempre serán evadidas por cuenta de la invención y creatividad de los operadores del mercado (Rodríguez Yong, 2013). 
cláusulas abusivas. ${ }^{9}$ A su turno, cuando una previsión contractual coincide con el supuesto de prohibición de la Circular Externa o de la Ley 1328 de 2009, esta será ineficaz de pleno derecho. Las mismas observaciones son aplicables sobre la autoridad de Industria y Comercio.

La justicia arbitral puede antojarse una interpretación menos apegada al tenor de la necesidad: ${ }^{10}$ los laudos siguen una línea de pensamiento injustificado, es decir, una cláusula abusiva injustificada lo es, porque degenera en una situación sin causa en el contrato para las partes. No es más que un desequilibrio normativo, sin interesarse en realidad por las causas mediatas del conflicto. ${ }^{11}$

La Corte Suprema de Justicia - en la época de la Corte de Oro, conocida por sus hábiles razonamientos jurídicos- señala un punto de inflexión en el entendimiento de las cláusulas abusivas. El doctor Zuleta Ángel aplica la teoría de la causa para eliminar de un contrato una cláusula abusiva. ${ }^{12}$ Esta tesis es reiterada en 1968 por el doctor Ospina Fernández:

9 En la Sentencia C-909 de 2012, la Corte Constitucional zanja la discusión jurídica sobre la competencia de la Superintendencia Financiera para emitir listas negras de cláusulas abusivas. Tal discusión nació del límite entre el poder legislativo y el ejecutivo, ya que, en principio, este ente no debería poder establecer criterios de restricción a la libertad contractual. No obstante, la Corte lo autoriza, al decir que se está ante un criterio de intervención económica y permisión de la ley que no rompe con el equilibrio de poderes. Estos mismos argumentos son dables frente a la Superintendencia de Industria y Comercio.

10 Múltiples son las sentencias sobre el particular, como la del caso del 25 de marzo de 2009, Megaenlace Net S.A. vs. Telefónica Móviles Colombia S. A.; el del 14 de diciembre de 2006, Comcelulares F. M. Ltda. vs. Comcel S. A.; también es interesante el Laudo Arbitral del 1 de diciembre de 2006, Concelular S. A. -en liquidación- vs. Comunicación Celular S. A. -Comcel S. A.-; el del 18 de julio de 2005, José Manuel Espinosa vs. Fiduestado S. A. y Banco del Estado S. A.; el del 12 de febrero de 2004 del Consorcio Business Ltda. vs. Bellsouth Colombia S. A. y el del 15 de noviembre de 2002, de Adriana María Calderón Palacio vs. Cafesalud Medicina Prepagada S. A.

11 El Tribunal de Arbitramento (2009) decidió el caso entre Megaenlace Net S. A. contra Telefónica Móviles de Colombia S. A., con fecha de marzo 25 de 2009: “Mientras que la estipulación emane la voluntad común de las partes, es absolutamente vinculante y válida".

12 "En estas condiciones corresponde al juez investigar si tal o cual cláusula litigiosa ha sido verdaderamente aceptada por las partes o si su inserción en el reglamento compacto y misterioso constituye una trampa para una de ellas. En esta última eventualidad, el tribunal, en nuestro sentir, tiene el poder de descartar la autoridad de esta cláusula, sobre todo si ella no guarda armonía con las cláusulas esenciales que constituyen la trama misma de la operación y que han sido conocidas por los interesados y aceptadas por éstos [...]. Cuando una cláusula puede pasar por imprecisa, oscura o ambigua, los tribunales aprovechan eso para usar ampliamente su poder que se les reconoce de investigar la intención de los contratantes y de interpretar la póliza en favor de la parte que se obliga, es decir, del asegurado" (Corte Suprema de Justicia, 1936b). 
Como dice Josserand: ni la igualdad económica, ni la igualdad verbal son condiciones necesarias de validez de los contratos: basta con la igualdad jurídica [...] es que la ley misma, no el juez, es la que se preocupa por evitar la inserción de cláusulas leoninas en los reglamentos de la empresa (cursivas propias) (Corte Suprema de Justicia, 1968). ${ }^{13}$

El criterio causalista es medio para suprimir una cláusula abusiva como en 1936, pero ahora también es criterio de identificación de la misma.

La identificación de las cláusulas abusivas con la teoría de la causa es reiterada por la Corte Suprema de Justicia en $1974^{14}$ y en 1994, pero en esta última decisión hay un viro: lo que parecería clara fuente jurídica se toma como causa del conflicto. La Corte establece que una cláusula es abusiva por cuanto se está ante la violencia económica de una de las partes, razón por la cual dicha previsión debía ser eliminada.

Esto revela que la jurisprudencia mantuvo una posición lógica, que parte del razonamiento causa-consecuencia. Tal posición se confundió con las causas mediatas de una situación abusiva, mas no implica la pérdida de la lógica de los razonamientos anteriores. Si existe un desequilibrio normativo del contrato, este se comprueba por medio de las cargas prestacionales de las partes, sin interesar la fuente que motivó dicho desbalance. Para el caso expuesto en 1994, la Corte propuso la violencia económica, aunque sigue reiterando que una previsión errónea o abusiva es aquella que degenera en un "desequilibrio injustificado". Entonces, la Corte usa una herramienta mediata y toma como naturaleza jurídica aquella cláusula sin causa de existencia, es decir, un desequilibrio normativo sin causa jurídica de existencia.

Si se lee con cuidado, en todas las decisiones de cláusulas abusivas siempre estará presente el desequilibrio normativo, sin interesar ante cuál

13 "[...] tampoco es exacto que el contrato de seguro por su esencia [...] haya de encasillarse en los contratos de adhesión [...]. En conclusión: no es cierto, como lo pretende la censura, que el contrato de seguro, aunque se celebre por adhesión, no admita en toda su amplitud la operancia del postulado de la autonomía de la voluntad privada [...]" (Corte Suprema de Justicia, 1968).

14 "La escuela Aristotélica-Tomista [...]. La equidad, de acuerdo con esta concepción es definida como la moderación de las disposiciones de la ley, en algunos casos particulares mediante su armonía con la suprema igualdad de la justicia natural [...]. Considera la Corte, que, de los criterios expuestos, el interpretativo de cláusulas contractuales de que se habla, es el que más exactamente se ajusta a su naturaleza de la estipulación, y el que mejor garantiza a las partes su derecho" (Corte Suprema de Justicia, 1974). 
evento se esté, sea de violencia económica, dolo o buena fe (Tribunal de Arbitramento, 2009).

\subsection{La teoría de la causa ${ }^{15}$}

El profesor Mazeaud (2009) expresa que la causa "está siendo explotada, desde la perspectiva de una exigencia creciente del equilibrio contractual [...] para operar un control de proporcionalidad en las convenciones" (p. 124). La causa ya ha sido atraída por la doctrina y la jurisprudencia francesa (Mazeaud, 2009), ${ }^{16}$ no es más que nombrar el famoso caso Chronopost, ${ }^{17}$ como un principio intrínseco y moral de control al contenido del contrato que, en palabras de la profesora Lasserre-Kiesow (2009), sobre la discusión del Consejo de Estado francés acerca del Código Civil, "La noción de causa del contrato o de la obligación ha devenido en un instrumento de control del equilibrio entre prestación y contraprestación" (traducción propia) (p. 12).

Entonces, recurrir a la causa como institución de control a la proporcionalidad del contrato es un criterio fuerte para corregir la esencia operativa de una cláusula abusiva: el desequilibrio. Para ello, se debe explicar el qué y su importante consecuencia. En el último aparte radica la propuesta de solución al problema de causas mediatas y real fuente jurídica del Derecho.

\subsubsection{Noción}

El caso Clement-Bayard en el tribunal de Compiège, del 19 de febrero de 1919, es potísimo. Si bien se está ante el hecho del abuso, el juez cambia la dirección del discurso. Se indica que los derechos se usan de acuerdo y conforme con la finalidad para la cual nacieron y que, si se actúa con otro

15 Sobre la historia, puede verse Pérez Vives (1953).

16 Sentencia del 14 de octubre de 1997 y del 8 de febrero de 2005 de la Sala Comercial de la Corte de Casación francesa. Primera Sala Civil, sentencia del 11 de marzo de 2003. Primera Sala Civil, sentencia del 3 de julio de 1996. Es importante rescatar: "[...] la nullité d'un contrat de location a été prononcée, sur le fondement de l'absence de cause, parce que l'exécution du contrat selon l'economie voulue par les parties (était) imposible".

17 Se entendió por no escrita una cláusula de limitación de responsabilidad, por cuanto dejaba desprovista de causa la contraprestación del expedidor y desequilibraba la ecuación normativa del contrato (Rocha Alvira, 2009). 
fin, se acciona de modo abusivo. Sin embargo, al no encontrarse un daño, la categoría de solución es la teoría de la causa. Lo mismo ha de pasar en Colombia.

El Código de Bello dicta que la causa debe ser real y lícita (Código Civil, art. 1.524). Este postulado podría reducirse a lo siguiente: todo lo que se haga en el mundo jurídico debe conocer un fin. En el contrato, cada parte tiene una serie de derechos y cargas entre sí, que se sustentan en la causa en un plano derecho/obligación y, en efecto, el contrato se rige por la conmutatividad de sus prestaciones. Aquí reside uno de los problemas más interesantes: ¿la causa es de la obligación o del contrato? ¿Es de ambas?, como lo dirían Alessandri, Somarriva y Vodanovic (1998) ¿O es excluyente? (Mazeaud, 2009).

El régimen jurídico de la causa está presente en diversos artículos del Código Civil y en desarrollos de la doctrina como la excepción de contrato no cumplido, el desistimiento tácito (Brugi, 1946), la teoría de la pérdida de la cosa y la condición resolutoria tácita, entre otros institutos; sin profundizar en demasía al respecto, del Artículo 1524 se derivan dos consideraciones: a) se encuentra situada en el Libro IV, Título II, del Código Civil: "De los actos y declaraciones de voluntad". Esto es indicativo de que la causa, como elemento, solo está en los actos o las declaraciones de voluntad, y b) del mismo Artículo 1524:

No puede haber obligación sin una causa real y lícita; pero no es necesario expresarla. La pura liberalidad o beneficencia es causa suficiente.

Se entiende por causa el motivo que induce al acto o contrato; y por causa ilícita la prohibida por la ley, o contraria a las buenas costumbres o al orden público.

Así, la promesa de dar algo en pago de una deuda que no existe, carece de causa; y la promesa de dar algo en recompensa de un crimen o de un hecho inmoral, tiene una causa ilícita (cursivas propias).

La doctrina ha separado en tres la causa de los contratos: en los gratuitos, la causa es la mera liberalidad; en los reales, la entrega de la cosa y, en los onerosos, la contraprestación. De la lectura del Artículo, se extrae que el Código Civil se refiere a la causa del contrato, en razón a que el primer inciso trata sobre el acto gratuito. En el segundo, la clara referencia al contrato o acto. ¿Cómo armonizar lo anterior con el primer inciso? 
"No puede haber obligación sin causa real y lícita" (cursivas propias). Con las consideraciones hechas, la causa de las obligaciones es una institución solo de los contratos, lo que implica que aquí la obligación es el conjunto de obligaciones y contraprestaciones a las que se obligan las partes, como lo refirió el profesor Uribe Holguín (1974). Es irrelevante si la obligación tiene una causa; esta solo existe como hija dilecta de la autonomía de la voluntad. Lo que sí puede ser controlado es aquello relativo a la fuente de la obligación -el contrato o la convención, en este caso-, pues la causa está ligada al principio de justicia conmutativa.

En los contratos onerosos, la causa es una institución jurídica de relevancia social (Lasserre-Kiesow, 2009), porque los objetos del contrato entre los participantes son sus contraprestaciones mutuas y, a su turno, sus causas recíprocas. Cada quien contrata por lo que su contraparte hará y viceversa, como lo expresa el maestro Pérez Vives (1953): “[...] existe en los contratos bilaterales una correlación entre las obligaciones recíprocas de las partes, en virtud de la cual cada una de ellas se compromete únicamente en consideración a la prestación que la otra ofrece" (p. 59). ¿Qué pasa cuando este interés es insuficiente? Se está en sede de una causa irreal o ausencia de causa, que ilustra el profesor Pérez Vives (1953) por medio de ejemplos:

La ausencia de causa. Puede presentarse en aquellos casos en que una obligación carezca de contrapartida o que la obligación de uno de los contratantes carezca de objeto. Ejemplos: seguro pactado para cubrir un riesgo inexistente; venta de cosas que se supone existir y no existen, etc. (pp. 298-299).

Si bien los ejemplos anteriores son indicativos de la figura de ausencia de causa, para el objeto de esta reflexión interesa la ausencia de contrapartida o contraprestación parcial en el contrato.

Esto no es otra cosa que el dolus res ipsa, institución romana que, sin importar las personas de la relación de obligación, observa el equilibrio en sí mismo desde las condiciones del contrato: es la causa, como criterio objetivo.

Por esto, según el Artículo 1524 del Código Civil, no puede haber obligación sin causa real, sino una sanción de inexistencia; lo que supone es un principio: la conmutatividad del contrato. 
La conmutatividad o equivalencia de prestaciones ha sido tomada en cuenta por la jurisprudencia nacional en diversos fallos. A manera de ejemplo, la Corte Suprema de Justicia (1936a) dijo:

Las reglas jurídicas especiales de los contratos sinalagmáticos tendientes todas ellas a conservar la simetría contractual exigida por la reciprocidad o correlación de las obligaciones surgidas de la convención bilateral -se explica por la noción de causa de las obligaciones [...].

Asimismo por la doctrina, desde el caleidoscopio del Derecho francés (Rocha Alvira, 2009).

En materia, una cláusula abusiva injustificada degenera en el contrato un desequilibrio normativo, entendida esta disparidad como aquella entre derechos y obligaciones (Lasserre-Kiesow, 2009). Esto no es otra cosa que una ausencia de causa o, al menos, una causa insuficiente para uno de los partícipes. En otras palabras, en la búsqueda de equidad contractual, cuando no se llega a la lesión enorme, pero tampoco se está ante la justicia y las prestaciones recíprocas no son suficientes, uno de los contratantes no ve satisfecho su interés económico en el contrato: su objeto contractual no se justifica, en y por la contraprestación de su contraparte, por lo que se necesita un requilibrio (Cárdenas, 2009b). ${ }^{18}$

Este requilibrio no es cualquier entidad o naturaleza, es decir, no opera cuando no puede solaparse la causa de los contratantes: las obligaciones recíprocas. Lo anterior se debe a que la causa de las obligaciones no debe expresarse, como lo dispone el mismo Artículo 1524 del Código Civil; más, cuando, en sede de los contratos conmutativos, las obligaciones se miran como equivalentes, de acuerdo con lo dispuesto en el Artículo 1498 del Código Civil. Con todo, no es legítimo que el juez indague la causa en el fuero interno, salvo casos muy especiales, como se verá adelante (Pérez Vives, 1953).

¿Cuándo se rompe el equilibrio? Si se asume una cláusula como ajena a la justicia contractual, se supliría el criterio necesario de importancia o de incorrección significativa. Es el censor de la estipulación quien determina si

18 De este modo, se vería en plena aplicación el Artículo 13 de la Constitución Política de Colombia, al buscar el equilibrio cuando la necesidad social lo requiere. 
hay injusticia en el contrato; en consecuencia, la cláusula que desequilibra obedece al calificativo de abusiva injustificada (Corte Suprema de Justicia, 1994). No obstante esta ha de ser torticera. De nuevo se cae en la subjetividad del juzgador, pero la ley le obliga a mirar las condiciones particulares del negocio: es subjetivo, mas no arbitrario, ya que se parte de la base de que los contratantes proceden con juicio y prudencia (Pérez Vives, 1953).

Debe advertirse que la interdependencia, entonces, no implica equivalencia objetiva y matemática de las obligaciones contractuales. El desequilibrio debe ser significativo y romper el principio de conmutatividad; de lo contrario, se seguiría la regla del 1602 del Código Civil sobre la fuerza obligatoria del contrato (Pizarro, 2012).

Del Artículo 42 de la Ley 1480 se deriva: "Para establecer la naturaleza y magnitud del desequilibrio, serán relevantes todas las condiciones particulares de la transacción particular que se analiza" (cursivas propias).

De lo anterior, son pertinentes tres consideraciones: a) la Ley, al pedir que se establezca el desequilibrio, solicita un análisis desde la óptica de estar, potencialmente, ante un hecho fuera del campo de aplicación del Artículo 1602 del Código Civil; b) la magnitud del equilibrio es un rasero cuantitativo y cualitativo, y c) deben observarse todas las circunstancias extrínsecas e intrínsecas de la transacción, con el fin de instaurar la magnitud.

La norma da una puerta de entrada, un objetivo y un método, a saber, la posibilidad de irse lanza en ristre contra la aplicación absoluta de la fuerza obligatoria del contrato y la aplicación irrestricta de la autonomía de la voluntad; esto no quiere decir otra cosa que control entre el límite de la lesión enorme y el justo contrato, en búsqueda de un desequilibrio de magnitud considerable y por medio de las condiciones de la transacción particular. El punto está en señalar la significancia, para que el juzgador no sea arbitrario, pero pueda reconformar un contrato en y para las partes (Jiménez, 2015).

Sobre la significancia, el profesor Rodríguez Yong (2013) establece su necesidad, porque el simple desequilibrio no basta. ${ }^{19}$ En cita a un laudo arbitral de importancia manifiesta:

[...] es claro y también generalmente aceptado que no se trata de propender ni garantizar la milimetría contractual, por lo que entiende que

19 Ver también Tribunal de Arbitramento (2005). 
solo en casos de desequilibrios marcados y manifiestos, en detrimento de la posición contractual del adherente y/o beneficiario desproporcionado y exclusivo del predisponente, se justifica abrir espacio a la posibilidad de enjuiciamiento del contenido negocial (cursivas propias).

Marcado y manifiesto son dos palabras base para un test de significancia. ¿Cuándo el desequilibrio es manifiesto? Cuando existen relaciones de dominación de mercado, contratos de adhesión, asimetrías de la información y, en general, cuando una parte de la convención es débil. Aquí el desequilibrio basta con el punto medio: obligaciones que 1) carguen en exceso al deudor, y 2) en caso de no haber estado expuesto a circunstancias de debilidad o asimetría, no se hubieran pactado.

¿Cuándo es marcado? El desequilibrio es más exigente respecto al cumplimiento de la fuerza obligatoria del contrato, porque no se está ante una asimetría negocial o de mercado, ya que marcado, en este test, implica probar un desequilibrio que rompe con la conmutatividad del contrato: 1) inusual, y 2) que cuantitativa y cualitativamente sea en detrimento del patrimonio del deudor.

\subsubsection{De la nulidad relativa y reducción de obligaciones}

La consecuencia jurídica de una cláusula contractual sin causa que sustente su mantenimiento en el mundo del contrato es la nulidad relativa, como ultima ratio, pero esta solución debe ser armonizada con aquello que los operadores jurídicos ya han establecido. Primero, porque es práctico partir de la base de lo existente y, segundo, porque no habría contradicción.

Hay dos tesis que podrían estar encontradas: de un lado, la aplicación de la nulidad relativa y, por otro, la ineficacia de pleno Derecho. Sin embargo, esta oposición es virtual, porque como bien se ha establecido, las cláusulas abusivas pueden extenderse a todos los contratos, sin importar la causa de disparidad en él, solo si existe un desequilibrio normativo, sea marcado o manifiesto. Por tal razón, los entes de control sometidos a las normas ya creadas sobre cláusulas abusivas que tienen como método aplicar "se entiende por no escrita" deben seguir haciéndolo. No es contrario a la lógica práctica aplicar el remedio para una causa mediata, si logra ser eficiente. 
Entonces, en aplicación de la Ley 1480 de 2011 y otras, en materia de consumo, siempre que una obligación no tenga su contraprestación en el contrario, se entenderá por no escrita, así no esté en una lista negra.

Por otra parte, en el resto de relaciones jurídicas fuera de la aplicación de las normas del consumo, se deberá acudir a la nulidad relativa, entendida como la técnica de reducción de obligaciones (Pérez Vives, 1953) que, a todas luces, es una medida más eficiente y eficaz, en virtud de lo dispuesto en el Artículo 306 del Código de Procedimiento Civil, que en nada fue modificado por el Código General del Proceso: "Resolución sobre excepciones. Cuando el juez halle probados los hechos que constituyen una excepción, deberá reconocerla oficiosamente, en la sentencia, salvo las de prescripción, compensación y nulidad relativa, que deberán alegarse en la contestación de la demanda" (cursivas propias) (Código General del Proceso, art. 282).

En otras palabras, quien no se vea afectado por la cláusula nula, si no la alega, la convalida procesalmente.

La eficiencia también proviene de la posibilidad de saneamiento del vicio por parte de quien se vea afectado y, por ende, legitimado para alegar la nulidad o vicio. Lo anterior está contenido en el Artículo 1741 del Código Civil y no requiere mayores explicaciones.

En estos eventos, el juez calificaría una cláusula abusiva injustificada, por cuanto en el contrato crea una disparidad normativa. El contrato adolecería de causa irreal, razón por la cual es relativamente nula la convención que provoca el desequilibrio, porque es un vicio que afecta el contrato, no listado como causal de nulidad absoluta, como se describe en el último inciso del Artículo 1741 del Código Civil. Es necesario precisar que ese Artículo es atraído por el Artículo 822 del Código de Comercio en lo que respecta a otros vicios del acto jurídico no tipificados (anulabilidad).

Así, ante un desequilibrio marcado o manifiesto, ¿cuál cláusula se elimina? Las cláusulas accidentales deben perecer primero; de ahí, las demás en aquello que no desnaturalice la función económica o naturaleza del contrato, pues, de lo contrario, se estaría en sede de otra institución jurídica: la inexistencia del acto jurídico, que extralimita el objeto de este texto.

A su justo criterio, con fundamento en los artículos pertinentes sobre nulidad y en las normas sobre interpretación de contratos, el juez debe reducir la carga para la parte afectada, de forma que salve el contrato de 
su extinción: por medio de una técnica hermenéutica nacida del Artículo 1624 del Código Civil.

El juez, entonces, debe eliminar las obligaciones vía interpretativa y contextual (Corte Suprema de Justicia, 2011a) y seguir tres reglas: primero, las que sean abusivas y hayan sido predispuestas (Pothier, 1947); segundo, que sean abusivas y contrarias al deudor $\mathrm{y}$, tercero, en caso de no poder aplicar la regla del 1624 del Código Civil, todas aquellas obligaciones que adolezcan de causa bajo la premisa de la nulidad relativa o, en su defecto, cuando la solución mediata de alguna otra figura se muestre más eficiente (Parra Lucán, 2014).

En otros términos, sobre la última regla, a su justo criterio, el juez eliminará las cargas que considere marcadas o manifiestas contra el deudor, siempre a partir de las que menos daño produzcan en el acto jurídico como un todo, pero que aun así son consideradas como cláusulas injustificadas.

\section{Conclusión}

El sistema de Derecho continental impone el respeto a la ley escrita y de allí a la lógica que ella imprime sobre las relaciones jurídicas particulares. Desplegar una consecuencia jurídica a supuestos de hecho que no tienen por qué crearla violaría un principio básico de la lógica: la no contradicción.

Si existe un medio natural, que no se configura como excepción al régimen general, debe ser preferido sobre lo principialístico y lo extraordinario, porque esto da coherencia y vida a nuestro sistema de Derecho continental: es la teoría de la causa. Aprovechar el Artículo 1524 del Código Civil es sacar provecho a un tesoro de enorme calado (Cabrillac, 2009). ${ }^{20}$

Las cláusulas injustificadas, como en realidad deben llamarse, tienen su base jurídica en la teoría de la causa como especie y en la violación del principio de conmutatividad del contrato como género: las cláusulas injus-

20 Estas estipulaciones sin causa son víctimas y victimarios de la Ley de substitución. El profesor Cabrillac (2009) decía: "La fuerza de la práctica reside en una sabia alquimia de imaginación y de sabiduría, que debe resistir a la tentación de inventar un mecanismo substituible a otro sin haber apreciado su validez y sin haber medido sus consecuencias [...]. La creación de nuevos mecanismos jurídicos no debe ser abandonada a los aprendices de hechicero, pues la ley de substitución contiene numerosos riesgos, ilustración de su carácter potencialmente peligroso" (p. 215). 
tificadas no se restringen o limitan a las partes débiles, a los contratos de adhesión y mucho menos a supuestos de responsabilidad como lo requeriría el abuso del Derecho. Las previsiones violatorias de la conmutatividad del contrato deben ser eliminadas de la práctica negocial, porque no hallan causa jurídica en la relación bilateral, independientemente de la causa de esta disparidad negocial, sin perjuicio de estar ante alguna de las instituciones pertinentes y de las consecuencias que correspondan en Derecho.

Más allá del objeto de esta disertación, la teoría del control a las cláusulas abusivas no es más que la puerta de entrada a un principio olvidado del Derecho: la conmutatividad del contrato como herramienta de control social, cuando no se ha llegado a la lesión enorme, pero el contrato se muestra con desigualdad torticera a los ojos de los operadores jurídicos, es decir, cuando hay un desequilibrio marcado y manifiesto, si no están las anteriores dos condiciones, el Artículo 1602 del Código Civil sigue vigente.

El equilibrio normativo o intrínseco del contrato es una necesidad de ética en la libre autonomía de la voluntad y ahora, más que nunca, una necesidad, claro está, sin lesionar la seguridad jurídica. Según la Corte Constitucional (1993):

En todo caso, no será posible lograr la vigencia de un orden justo si la categoría del contrato, que por sí sola responde de una porción significativa de las relaciones sociales, no es examinada por el Juez y asumida por los particulares con un mínimo criterio de justicia sustancial.

Por medio de la causa, la igualdad encuentra su mayor escudero: "En esta forma, es la Ley Civil la que viene a configurar las especiales características de estructura de una sociedad determinada, más aún que la propia Constitución" (Pérez Vives, 1953, p. XIV).

\section{Referencias}

Alessandri, A., Somarriva, M. y Vodanovic, A. (1998). Tratado de Derecho Civil. Partes preliminar y general. Tomo II. Santiago: Jurídica de Chile.

Brugi, B. (1946). Instituciones de Derecho Civil con aplicación especial a todo el Derecho Privado. México D. F.: Uteha. 
Cabrillac, R. (2009). Sobre la ley de substitución y algunas de sus aplicaciones en derecho privado. En J. A. Gaitán, D. Juricic, F. Mantilla, M. A. Salah y M. Tapia (dirs.), Estudios sobre garantías reales y personales. Homenaje a Manuel Somarriva Undurraga (pp. 207-219). Bogotá: Universidad del Rosario, Universidad de Chile.

Cárdenas Mejía, J. P. (2009a). Justicia y abuso contractual. En F. Mantilla y F. Ternera (coords.), Los contratos en Derecho Privado (pp. 693-720). Bogotá: Legis, Universidad del Rosario.

Cárdenas Mejía, J. P. (2009b). La protección del contratante y la evolución del Derecho contemporáneo. En F. Mantilla y F. Ternera (coords.), Los contratos en Derecho Privado. (pp. 771-808). Bogotá: Legis, Universidad del Rosario.

Caumont, A. (2008). Teoría ética del contrato. El negocio jurídico contractual como ámbito de eticidad preordenado para la composición autonómica de conflictos de intereses. En F. Mantilla y C. Pizarro (coords.), Estudios de derecho privado en homenaje a Christian Larroumet (pp. 137-150). Bogotá: Universidad del Rosario.

Colombia, Congreso de la República. (1971). Código de Comercio. Bogotá: Voluntad. Colombia, Congreso de la República. (1972). Código Civil. Bogotá: Voluntad.

Colombia, Congreso de la República. (2009). Ley 1328.

Colombia, Congreso de la República. (2011). Ley 1480.

Colombia, Corte Constitucional. (2012). Sentencia C-909 del 7 de noviembre de 2012. M. P. Nilson Pinilla.

Colombia, Corte Suprema de Justicia. (1936a). Sentencia del 12 de diciembre de 1936, Sala de Casación Civil. M. P. Eduardo Zuleta Ángel.

Colombia, Corte Suprema de Justicia. (1936b). Sentencia del 29 de febrero de 1936, Sala Civil.

Colombia, Corte Suprema de Justicia. (1938). Sentencia del 21 de febrero de 1938.

Colombia, Corte Suprema de Justicia. (1968). Sentencia del 26 de marzo de 1968, Sala de Casación Civil. M. P. Guillermo Ospina Fernández.

Colombia, Corte Suprema de Justicia. (1974). Sentencia del 8 de mayo de 1974, Sala de Casación Civil. M. P. Ernesto Escallón Vargas.

Colombia, Corte Suprema de Justicia. (1994). Sentencia del 19 de octubre de 1994, Sala de Casación Civil. M. P. Carlos Esteban Jaramillo Schloss.

Colombia, Corte Suprema de Justicia. (2005). Sentencia del 28 de febrero de 2005, Sala Civil.

Colombia, Corte Suprema de Justicia. (2011a). Sentencia del 30 de agosto de 2011, Sala Civil.

Colombia, Corte Suprema de Justicia. (2011b). Sentencia del 14 de diciembre de 2011. Ref. C-1100131030142001-01489-01. M. P. Jaime Alberto Arrubla Paucar. 
Colombia, Corte Suprema de Justicia. (2013). Sentencia del 1 de noviembre de 2013, Sala Civil. M. P. Arturo Solarte Rodríguez.

D’Ors, Á. (1968). El Digesto de Justiniano. Pamplona: Aranzandi.

De Cupis, A. (1975). El daño: teoría general de la responsabilidad civil. Barcelona: Bosch. Estigarribia Bieber, M. L. (2000). Las cláusulas abusivas en la contratación con consumidores en la legislación argentina. Recuperado de http://www.unne.edu.ar/ unnevieja/Web/cyt/cyt/2000/1_sociales/s_pdf/s_037.pdf

Gil Echeverry, J. (2013). El abuso de las cláusulas contractuales. En A. Aljure, É. I. León, Y. López y C. A. Botero (coords.), Estudios de Derecho Privado. Liber amicorum en homenaje a Hernando Tapias Rocha. Bogotá: Universidad del Rosario. Jiménez Valderrama, F. (2015). Teoría del contrato y del negocio jurídico. Bogotá: Legis. Laguado Giraldo, C. A. (2003). Condiciones generales, cláusulas abusivas, y el principio de buena fe en el contrato de seguro. Vniversitas, (105), 231-251.

Lasserre-Kiesow, V. (2009). Contrat et morale. Los contratos en Derecho Privado. En F. Mantilla y F. Ternera (coords.), Los contratos en Derecho Privado (pp. 1-26). Bogotá: Legis, Universidad del Rosario.

Malaurie, P., Aynès, L. y Stoffel-Munck, P. (2005). Les obligations. Droit Civil. París: Defrénois.

Mazeaud, D. (2009). La notion de cause d'origine française. En F. Mantilla y F. Ternera (coords.), Los contratos en Derecho Privado (pp. 121-136). Bogotá: Legis, Universidad del Rosario.

Parra Lucán, M. Á. (2014). Negociación y perfección de los contratos. Pamplona: Thomson Reuters Aranzadi.

Pérez Vives, Á. (1953). Teoría general de las obligaciones (2a ed.). Volumen I, Primera parte. Bogotá: Temis.

Pérez Vives, Á. (1968). Teoría general de las obligaciones. Volumen II, Primera parte. Bogotá: Temis.

Pizarro, C. (coord.). (2012). El Derecho de los Contratos en Latinoamérica. Bases para unos principios de Derecho de los Contratos. Universidad del Rosario, Universidad Externado.

Pothier, R. J. (1947). Tratado de las obligaciones. Buenos Aires: Atalaya.

Rengifo García, E. (2014). Las Facultades Unilaterales en la Contratación Moderna. Bogotá: Legis.

Rocha Alvira, A. (2009). Lecciones sobre Derecho Civil: obligaciones (Martínez Cárdenas, B. M., rev.). Bogotá: Universidad del Rosario.

Rodríguez Yong, C. A. (2013). Una aproximación a las cláusulas abusivas. Bogotá: Legis, Universidad del Rosario.

Tamayo Jaramillo, J. (2007). Tratado de responsabilidad civil. Tomo I. Bogotá: Legis. 
Tribunal de Arbitramento. (2005). José Manuel Espinosa vs. Fiduestado S. A. y Banco del Estado S. A., del 18 de julio de 2005.

Tribunal de Arbitramento. (2009). Megaenlace Net S. A. vs. Telefónica Móviles Colombia S. A., del 25 de marzo de 2009.

Uribe Holguín, R. (1974). Teoría general de los contratos. Bogotá: Ediciones Rosaristas. 